\title{
Pautas para la determinación de la responsabilidad penal del médico en comisión por omisión
}

\section{POR LIUVER CAMILO MOMBLANC $(*)$}

Sumario: I. Introducción.- II. La comisión por omisión. Bases teóricas que inspiran su diseño dogmático.- III. La comisión por omisión. Una mirada al ordenamiento y la praxis jurídico-penal cubana.IV. Una propuesta para el ordenamiento jurídico cubano y la praxis judicial.- V. Consideraciones finales.- VI. Referencias bibliográficas.

Resumen: el médico ya no se considera como en el pasado una autoridad indiscutible y este fenómeno se aplica a todas las profesiones de responsabilidad pública o social. La complejidad de los procesos de responsabilidad médica en la actualidad requiere iniciativas de investigación que brinden propuestas de solución a los numerosos problemas que enfrentan los tribunales penales frente a estos casos. En este artículo, a partir de las bases teóricas que inspiran el diseño dogmático del comportamiento omisivo, se examina el ordenamiento jurídico penal cubano y propone pautas para la determinación la responsabilidad penal del médico en comisión por omisión; fuente de inagotables controversias, incluso en sus cuestiones más particulares que se agudizan en el ámbito médico.

Palabras claves: comisión por omisión - responsabilidad penal médica - Código Penal cubano

Lignes directrices pour la détermination de la responsabilité pénale du médecin en commission de l'omission

Résumé: Le médecin n'est plus considéré comme une autorité incontestable dans le passé et ce phénomène s'applique à toutes les professions à responsabilité publique ou sociale. La complexité des processus de responsabilité médicale nécessite actuellement des initiatives de recherche qui apportent des solutions aux nombreux problèmes rencontrés par les tribunaux pénaux dans ces affaires. Dans cet article, basé sur les bases théoriques qui inspirent la conception dogmatique du comportement par omission, le système judiciaire pénal cubain est examiné et propose des

(*) Prof. Auxiliar de Derecho Penal. Departamento de Calidad, Universidad de Oriente, Santiago de Cuba, Cuba. 
directives pour la détermination de la responsabilité pénale du médecin en commission pour omission; source de controverses inépuisables, même dans leurs problèmes les plus particuliers qui sont exacerbés dans le domaine médical.

Mots clés: commission pour omission - responsabilité pénale médicale - Code
pénal cubain

\section{Introducción}

La ciencia médica no escapa de los tentáculos sociales que signan la modernidad. El desarrollo tecnológico que la matiza y las incertidumbres que la rodean hacen más complejos los procesos en los que ha de establecerse la responsabilidad médica, lo cual desde sus primeras discusiones ha resultado una tarea de extrema complejidad. A ello contribuye, no sólo la doble naturaleza de la medicina como arte y ciencia, también los intríngulis al depurar los ámbitos en los que debe evaluarse: ético, administrativo, civil o penal. Esta última, calificada como una vasta zona gris en la que no siempre resulta fácil perfilar los presupuestos de intervención.

También se aprecia que la posibilidad de responsabilizar a los galenos ha ido en aumento con el decurso de los años. Esto, unido a la importancia que han adquirido los procesos de responsabilidad médica en las últimas décadas, exige de iniciativas investigativas sobre el tema. En este escenario se ubica como una de las cuestiones más ininteligibles, temidas por los estudiosos y operadores de la ciencia penal, la temática de la responsabilidad penal del médico en comisión por omisión. Temor que responde, como señala Pérez Duharte (2015), a que el Derecho Penal se ha diseñado esencialmente para delitos perpetrados por acción, intencionales y consumados. Asimismo, ejecutados por su autor directo o material; en tanto el resto de las variantes fácticas (omisión, comisión por omisión, imprudencia, tentativa y complicidad) son asuntos menos tratados dado lo enrevesado de las bases teóricas que en general inspiran su diseño dogmático.

Sobre la comisión por omisión, naturalmente las posiciones teóricas no son pacíficas. Entre otras obras destacan la de los clásicos alemanes, muchas de ellas traducidas por sus discípulos hispanos. También algunas fuentes escritas por estos (Bustos Ramírez y Hormazábal Malarée, 1997; Mir Puig, 2002; Muñoz Conde, 1991) seguidores de sus maestros alemanes y las obras de los cultores del Derecho Penal de América Latina (Creus, 1992; Fontán Balestra, 1998; Plascencia Villanueva, 2004; Zaffaroni, Slokar y Alagia, 2002). Sin embargo, el paisaje bibliográfico cambia bruscamente cuando se intentan identificar trabajos que enfoquen el análisis de esta modalidad de la conducta penalmente relevante en el caso de la actuación médica. En esta dirección destaca un capítulo en el libro La responsabilidad penal 
del médico de la profesora española Gómez Rivero (2003), cuyos conocimientos médicos y jurídicos, demostrados en otras obras precedentes, la convierten en un referente de obligada consulta para quien incursione en estos predios (Muñoz Conde, 2003).

La doctrina cubana dedica poco espacio al análisis de la problemática teórico-práctica que motiva estas cuartillas. Sobre la conducta omisiva destacan los oportunos planteamientos ofrecidos por Quirós Pírez (2005) en su Manual para el estudio del Derecho Penal y los contenidos en la Tesis en Opción al Grado Científico de Doctor en Ciencias Jurídicas de la profesora Pérez Duharte (2007) intitulada La autoría en los delitos omisivos. La primera de las obras, al tratarse de un texto dirigido fundamentalmente al pregrado, sólo desarrolla los elementos puntuales de esta institución del Derecho Penal General, sin profundizar en sus aspectos más controvertidos. La tesis doctoral precisa su campo de acción hacia la determinación de las formas de autoría en las diversas variantes del delito omisivo. No obstante, su autora realiza un valioso estudio de las peculiaridades de la omisión como forma de la conducta penalmente relevante, partiendo de las diferentes concepciones sobre la acción y las modalidades del comportamiento humano (1). Es por ello que fue utilizada como fuente de consulta, precedente investigativo y de referencia; así como por coincidir con nuestros propósitos algunas de las recomendaciones que realiza.

A esta situación se añade el escaso tratamiento de la temática por los juristas, sector en el que no se identifica en Cuba una investigación que sistematice y desarrolle lo relativo a la responsabilidad penal médica en comisión por omisión. En esta tesitura el terreno parece virgen e inexplorado. Ello permite afirmar que el tema ha adolecido de un adecuado desarrollo teórico en el país con trascendencia a los órdenes práctico y normativo.

\section{La comisión por omisión. Bases teóricas que inspiran su diseño dogmático}

Los delitos de comisión por omisión tienden a ubicarse en un espacio mayor que el mantenido hasta el momento, particular que justifica cualquier interés por su investigación. A ello se adiciona que, como forma particular de la conducta penalmente relevante desde su nacimiento ha sido, “(...) fuente de complejas e inagotables controversias, incluso en sus cuestiones más particulares" (Quirós Pírez, 2005, p. 284). Su estudio es, por ello, un verdadero océano de dudas e incógnitas

(1) Son algunos de los principales méritos de esta tesis: el tratamiento de la conducta omisiva, sus especificidades típicas al interno de la legislación penal cubana y la valoración de las exigencias que las diferentes modalidades de omisión imponen a la determinación de las formas de autoría. 
dentro de las cuales hemos escogido algunos aspectos que juzgamos cardinales como patrón analítico en interés de la comprensión del no menos controvertido tema: La responsabilidad penal del médico en comisión por omisión. En este sentido, se hace una breve referencia a la naturaleza, clasificación y estructura de los delitos cometidos bajo esta variante de la conducta, en cuyo centro de debate se posiciona el deber de garante y su equivalencia estructural con la comisión activa.

La comisión por omisión (doctrina francesa), también conocida como omisión impropia (doctrina alemana) se produce cuando es vulnerada una norma prohibitiva a través de la infracción de una norma imperativa o de un especial deber jurídico. Suele decirse que el sujeto no hace lo que debe hacer y produce un resultado que no debe producir. Son aquellos supuestos en los cuales el autor mediante un no hacer (conducta omisiva) al que viene obligado, produce un resultado comisivo (Bacigalupo, 1996; Baquero Vernier, 1983; Cobo del Rosal y Vives Antón, 1987; Creus, 1992; Quirós Pírez, 2005).

Unos ejemplos servirán para ilustrar lo expresado. Es el siempre citado caso de la madre que mata al hijo dejando de amamantarlo (muere por inanición). Asimismo, la enfermera que no suministra el medicamento prescripto al enfermo que cuida; el cirujano que reconoce en el lesionado a un antiguo enemigo y decide aprovechar la ocasión para abstenerse de intervenirlo quirúrgicamente y de este modo causar su deseada muerte. La madre y el cirujano porque violan el mandato que prohíbe matar, omitiendo el hacer al que estaban obligados que hubiese impedido la muerte; la enfermera, porque viola el mandato que prohíbe lesionar omitiendo el hacer al que viene obligada por razón de su profesión (Creus, 1992; Quirós Pírez, 2005).

Aunque existe cierto consenso entre las diferentes aproximaciones conceptuales de los delitos de comisión por omisión, no se puede decir lo mismo en torno a su naturaleza. En esta dirección se encuentran diversas posturas que se resumen, siguiendo la sistematización que realiza Pérez Duharte (2007) en: 1) la plena asimilación de la comisión activa y la comisión por omisión; 2) los que tratan de encontrar desde perspectivas normativas, los elementos propios de la comisión activa en específicas situaciones omisiva; 3 ) los que apuntan que, a pesar de que los delitos de comisión por omisión puedan ser relacionados con la causación activa atendiendo a la no evitación del resultado, desde el punto de vista de la forma de conducta, siguen siendo delitos omisivos y; 4) los que identifican la pertenencia de la omisión impropia a una tercera forma de la conducta humana. Al respecto Quirós Pírez (2005) señala que

En ocasiones se ha negado toda diferencia entre los delitos de comisión por omisión y los delitos de comisión; y a veces la comisión por omisión se ha incluido dentro de los delitos omisivos, denominándo- 
le entonces "delitos de omisión impropia". Esa oposición entre las dos opiniones aludidas favorece la adopción de un criterio que parece ser el más lógico: el delito de comisión por omisión representa una forma independiente de la figura objetiva (p. 284).

Según ese propio autor, atendiendo a esta modalidad de la conducta, los delitos se han clasificado en de comisión por omisión de configuración legal y de configuración judicial. Los primeros son aquellos establecido de forma expresa por el legislador en la ley; los segundos, en los que es el tribunal, al momento de aplicar la norma, el que lleva a cabo su construcción, por no existir en la ley una formulación que de modo expreso lo prevean. Estos últimos son los que generan mayor dificultad en el orden práctico “(...) por cuanto de lo que se trata es de determinar si las figuras delictivas que se encuentran previstas en la ley como de hacer, pueden perpetrarse - y hasta qué punto- no haciendo" (Quirós Pírez, 2005, p. 285). Corresponde al juez, porque no lo hizo el legislador en el momento de la previsión normativa, aplicar por vía de interpretación, la figura de delito prevista en la norma, pero en relación con su comisión por omisión. Es, por ello, que la doctrina se ha referido a estas figuras de delito que son imputadas bajo el esquema de la omisión impropia de configuración judicial, como tipos penales no escritos o tipos penales de interpretación ( $v$. gr. En el homicidio, la ley pune al que mata, pero literalmente no pune al que no impide la muerte). Y en consecuencia señala que

La adaptación de los delitos de resultado a las particularidades de la comisión por omisión, se materializa - conforme se ha visto- por la vía de interpretación judicial. El principio de legalidad, por ello, puede experimentar cierto menoscabo, en la medida en que la figura aparece entonces sólo en parte legalmente determinada (Quirós Pírez, 2005, p. 286).

De igual modo, Bacigalupo (1996) manifiesta que estos casos de omisiones que no están tipificados expresamente y que consisten en la no evitación de una lesión de un bien jurídico cuya lesión está protegida frente a acciones positivas, se sancionan por derecho consuetudinario, según las penas previstas para el correspondiente delito de comisión. En consecuencia, considera que la constitucionalidad, es decir, la compatibilidad de esta categoría con el principio de legalidad no está totalmente fuera de duda. En este sentido, Carlos Creus (1992) también destaca el cuestionamiento que un sector de la doctrina realiza a esta modalidad de la conducta penalmente relevante por lo que su reconocimiento pudiera significar de afectación al principio de legalidad. Sin embargo, sostiene que

Si por un lado se plantea esa objeción, por el otro, dejar de reconocerlos importaría poner al descubierto un amplio campo de permisividad al ataque del bien jurídico que el mismo tipo comisivo protege; en 
consecuencia, los tipos omisivos impropios aparecerían como el agotamiento necesario del contenido prohibitivo del tipo escrito (p. 181).

Las peculiaridades de esta modalidad plantean la necesidad de profundizar en los elementos que caracterizan las figuras de delito que admiten la comisión por omisión. Para ello, también se sigue la sistematización desarrollada por Pérez Duharte (2015) quien sobre su núcleo duro o parte objetiva muestra la siguiente estructura: a) la existencia de una situación típica que tiene como premisa o presupuesto mínimo la posición de garante del sujeto activo; b) la ausencia de una acción determinada que implica la producción del resultado típico y; c) la capacidad de realización, seguida por la posibilidad de evitar dicho resultado, además de verificar, (con probabilidad rayana en la certeza), la relación existente entre la producción del resultado y la omisión de una acción debida.

Sobre la situación típica, señala que describe el deber de actuar del sujeto, combinado en estos casos con la llamada posición de garante. Ello significa que sólo podrá ser autor de un delito en comisión por omisión quien tiene una específica misión de protección de determinados bienes jurídicos, al punto de serle exigida una postura concreta en función de su tutela, expresada de alguna forma en el tipo penal (Pérez Duharte, 2015). Esta posición que se fundamenta en la estrecha relación del omitente con el bien jurídico, viene a constituir una suerte de presupuesto mínimo cuya función es la de depurar el círculo de posibles sujetos activos. También “(...) tiene el sentido de descartar la consideración de tales delitos cuando sus autores no reúnen las características de garantes (...)" (Creus, 1992, pp. 182-183).

En esta línea de pensamiento, resulta ilustrativa la referencia que realiza Carlos Creus (1992) a la "Obligación jurídica de actuar, posición o situación de garante", cuando expresa que

La doctrina, para referirse al grupo de autores que pueden serlo de estos delitos, emplea la expresión posición o situación de garante, queriendo significar con ella que sólo quien tiene la obligación jurídica de preservar el bien de que se trata mediante un hacer modificatorio de la realidad o impeditivo de esa modificación, puede asumir dicho papel (p. 180).

Asimismo, Tamarit Sumalia como se citó en Gómez Rivero (2003), sostiene que

El garante sería aquel sujeto a quien la comunidad jurídica tiene por responsable de una determinada situación, lo cual permitirá que le sea atribuido a su esfera de responsabilidad aquel resultado típico que debiera haber evitado. Tal atribución no será posible cuando el hecho se 
haya desarrollado exclusivamente (o de modo predominante) dentro del ámbito de responsabilidad de la víctima a proteger (p. 468).

Así, la posición de garante aparece como un componente no escrito añadido al tipo penal comisivo. Una de sus complejidades radica efectivamente en la fijación de los criterios para la determinación de las personas obligadas, en cada caso concreto, a garantizar que el resultado que lesiona o pone en peligro el bien jurídico no se produzca. Resulta esta una de las cuestiones más controvertidas del tema. No obstante, todas las posiciones conducen a la configuración de un catálogo de fuentes del deber de garante que tributan, con sus aciertos y desaciertos, al mismo objetivo. En este recorrido se identifican, la ley y el contrato, como las fuentes más antiguas del deber de garante (Quirós Pírez, 2005). Posteriormente se adicionó la idea del llamado hecho o actuar precedente del autor que pone en peligro el bien jurídico. Sus defensores plantearon que existe un deber de actuar cuando una persona coloca a otra (también conocido como injerencia) en una situación de la que no puede escapar con vida sin la ayuda de aquella; y si en este supuesto el obligado omite actuar, entonces, se convierte en culpable del resultado típico. Sin embargo, el profesor Quirós Pírez (2005) manifiesta que, salvo la ley, el resto de las fuentes citadas, resultan cuestionables. Incluso, expresa que, a su juicio, la concepción del contrato como fuente del deber de garante debe ser revisada conforme a la tesis que en la actualidad se aduce en cuanto a la aceptación voluntaria. En consecuencia, "tales planteamientos condujeron a una excesiva jerarquización de las fuentes formales que llevó, en ocasiones, a olvidar que la posición de garante debe existir en relación con el bien jurídico dañado" (Pérez Duharte, 2015, p. 171).

Con vista a las diferentes críticas de las que fueron objeto la teoría del deber de garante sustentada en las fuentes formales, surge la teoría funcional de las posiciones de garante. Conforme a ella se procura explicar la posición de garantía a partir de criterios materiales que agrupan luego en dos direcciones coincidentes con las funciones que incumben al garante (omitente), cuya infracción origina la responsabilidad penal a título de comisión por omisión: la función de protección de bienes jurídicos determinados y las funciones que surgen de un deber de control de una fuente de peligro. Según la función protectora, el garante debe proteger el bien jurídico contra todos los ataques que pudiera sufrir, cualquiera que fuera su origen (Quirós Pírez, 2005). Dicho deber puede surgir, en razón de relaciones personales de cuidado (clásico caso de los deberes de los padres con sus hijos); en relación con la posición de un órgano representativo (situación de las personas jurídicas y la actuación mediante su núcleo de poder); por estrechas relaciones de comunidad (comunidad de peligro y comunidad de hogar, personas que conviven bajo un mismo techo), y en razón de una función de protección ( $v$. gr. Las personas que disfrutan de una piscina depositan su confianza en el sujeto que se desempeña como salvavidas) (Pérez Duharte, 2015). 
Mientras que, según la función de vigilancia, corresponde al garante vigilar toda fuente de peligro que, puesta a su cuidado y custodia, pueda lesionar o amenazar cualquier bien jurídico ajeno (Quirós Pírez, 2005). Se trata de deberes que al decir de Pérez Duharte (2015) surgen de la vigilancia que ha de ejercerse sobre las fuentes de peligro ubicadas en los propios ámbitos de dominio material. Así, por ejemplo, dueños de animales peligrosos, construcciones que encierran algún tipo de peligro, industrias, entre otros. También aquellos que provienen del control que debe tenerse sobre el actuar de terceros como ocurre en el caso de la responsabilidad por el actuar de incapaces o menores, exigible a tutores y padres.

Consecuentemente, la perspectiva de solución debe ubicarse en la integración de ambos puntos, formal y material (teoría material-formal); el primero dirigido a esclarecer las relaciones del sujeto con respecto al bien jurídico y el segundo a valorar las respectivas fuentes de donde surgen tales relaciones. Unido a las ideas de que la posición de garante depende de la relación personal del sujeto con el bien, es decir al omitente no le es ajeno el interés protegido, y a la posibilidad real de que dicho sujeto pueda evitar el resultado; se logra así conformar una visión más uniforme y entendible de la posición de garantía en la situación típica descrita en los delitos de comisión por omisión (Pérez Duharte, 2015, pp. 172-173).

Algunos autores (Luzón Peña, 1996) sostienen que lo único importante para evaluar la existencia de una conducta penalmente relevante en su variante de comisión por omisión, es que pueda considerarse su equivalencia estructural con la comisión activa (juicio de identidad estructural). Para ellos sólo es necesario que la no evitación del resultado equivalga según el sentido de la ley a su causación activa, al margen de que el omitente se califique o no como garante. Exigencia de estricta identidad estructural entre el comportamiento activo y la comisión omisiva que integra los incisos b) y c) relativo a elementos que caracterizan las figuras de delito que admiten la comisión por omisión, expuestos ut supra.

Creemos que no deben existir dudas acerca de la importancia de verificar la equivalencia estructural con la comisión activa en estos casos. Primero, porque de no exigirse este requisito se incurriría en el riesgo de desenfocar el genuino contenido de injusto que posibilita el castigo de la omisión como si se tratase de una conducta activa. Segundo, derivado de lo anterior, resultaría un desmesurado ámbito de punibilidad, en cuanto que sería suficiente apreciar la posición de garante - en el caso de los que exigen este requisito- o una omisión que de algún modo contribuye al resultado - para los que no exigen dicha posición de garante-, para atribuir al omitente, con independencia de la índole de su contribución al suceso y la proximidad con el peligro que se acaba materializando en el resultado, responsabilidad por el mismo (Gómez Rivero, 2003). 
No obstante, también defendemos la importancia de la dilucidación del deber de garante. Esta exigencia constituye uno de los parámetros de diferenciación de esta variante de la conducta con la omisión propia, pura o simple. Nótese que en estos supuestos el tipo penal se agota en la desobediencia a la norma de mandato. En la gran mayoría de los casos resulta indiferente a efecto de su caracterización la producción de un resultado. La norma vulnerada es de esencia imperativa al ordenarse la realización de una conducta que el sujeto, bien deliberada o imprudentemente, no la realiza por lo que la solución legal sigue encontrándose en normas positivamente establecidas. No ocurre así en los supuestos de omisión impropia, en el que se produce una simbiosis normativa, expresada en la dualidad de las normas afectadas. Una genérica y prohibitiva, que dispone no producir el resultado, y otra concreta e imperativa que ordena efectuar el acto omitido que evitaría la producción del resultado. En consecuencia, la respuesta legal la ofrece el orden jurídico en su visión sistémica y el intérprete debe relacionar el tipo penal de acción con el sustento reglamentario de donde brota la obligación del garante (Pérez Duharte, 2007).

El segundo momento del tipo objetivo en los delitos de omisión impropia se obtiene al unir la ausencia de la acción debida con la producción de un resultado obtenido por esta causa. Esto resulta significativo porque se traduce en que no toda omisión jurídico-penal que provoca un resultado constituye comisión por omisión. Para ello se requiere de la concurrencia de la posición de garantía y de la capacidad del sujeto para evitarlo. De lo contrario, pese a la presencia del resultado, la ley penal podrá a lo sumo apreciar un delito de omisión pura.

Finalmente, otros de los aspectos polémicos de la fisonomía del delito de comisión por omisión de necesario tratamiento para su completa comprensión es lo relativo al elemento subjetivo. En general, se considera que esta modalidad de la conducta penalmente relevante admite tanto la intención como la imprudencia. Ahora bien, para su configuración dolosa la intención del sujeto debe alcanzar tanto la omisión de la acción debida como la posibilidad y necesidad de evitación del resultado. Significa que para su imputación a título de dolo el garante debe conocer que se trata de una situación en la que le corresponde intervenir y voluntariamente opta por no realizar el mandato impuesto (dolo directo), o bien porque permite la producción de un resultado que podía evitar con su proceder (dolo eventual). Mientras que para su atribución por imprudencia (culpa consciente o inconsciente) es necesario que la persona sea responsable por expresión normativa de haber adoptado las medidas de precaución que al omitir no evita la situación antijurídica creada (Pérez Duharte, 2015).

Hasta aquí se aprecia, en torno a la comisión por omisión, que no se descubre nada nuevo si se afirma el grado de dificultad que la rodea. Tampoco es de extrañar 
que su elaboración conceptual y el trazo de sus perfiles jurídicos penales en el orden teórico y en su aplicación práctica, haya generado tantas posturas como dificultades e interrogantes; así como los reparos por su cierta confrontación con el principio de legalidad, con énfasis en su modalidad de configuración judicial. Sólo a través de interpretación dirigida a relacionar el tipo penal escrito, con la figura del garante y la fuente de donde surge tal obligación de cuidado, podrá obtenerse la configuración de la situación típica. En consecuencia, la imputación de los hechos que se juzgan por un delito de comisión por omisión (Pérez Duharte, 2007). Sólo así, en cierta medida, se reconduce la estructura de la comisión por omisión en un plano en que lo legal y lo justo se concilian y salvaguarda el principio de legalidad.

\section{La comisión por omisión. Una mirada al ordenamiento y la praxis jurídico-penal cubana}

El Código Penal de Cuba establece los delitos de homicidio y lesiones que, ajustados a las normas de la imprudencia estipuladas en su Parte General, constituyen los tipos legales aplicables a los efectos de sancionar los hechos dañosos que acontecen como resultado de la negligencia, la impericia, la imprudencia y la inobservancia de los reglamentos en el actuar médico (2). De este modo se ofrece solución a las problemáticas generadas por la responsabilidad penal del médico. A la vez, para su delimitación y configuración se ha de recurrir a normativas de rango inferior ubicada fuera de la ley penal, que enmarcan tales conductas en el incumplimiento por parte de un sujeto activo determinado, de las obligaciones que le venían impuestas por ley y el propio ejercicio de su profesión (deber de cuidado).

Se obligan así a que, al momento de juzgar, se conforme mediante una interpretación judicial y partiendo de las formulaciones legales de cada delito referido, un tipo penal delictivo que se inserta dentro de los llamados delitos de comisión por omisión, al cumplir en su nueva estructuración con cada uno de los caracteres, condiciones o requisitos que lo conforman. En estos casos se configura la situación típica a través de la labor del intérprete ( $v$. gr., el juez), cuando relacione el tipo activo escrito (homicidio o lesiones) contentivo del bien jurídico protegido (vida o integridad corporal), con la figura del garante (el facultativo) y la fuente de donde surge tal obligación de cuidado (en nuestro caso en que existe un monopolio estatal de la asistencia médica se trata, en principio, de una fuente legal).

(2) Artículo 261 (homicidio): el que mate a otro, incurre en sanción de privación de libertad de siete a quince años. Artículo 272. 1. (lesiones): El que cause lesiones corporales graves o dañe gravemente la salud a otro incurre en sanción de privación de libertad de dos a cinco años. Ambos preceptos en relación al en relación a los artículos 9.1.3 y 48 Vid. (Rivero García y Bertot Yero, 2013). 
La existencia de un deber jurídico que radica fuera del tipo es fundamental para la integración de estas figuras delictivas, pero el sentido del tipo legal es el que decidirá si es o no admisible la equiparación de la comisión por omisión a la comisión activa (Luzón Cuesta, 1997). Ahora bien, ¿cómo se representa y debe ser resuelto en el caso de los delitos por imprudencia médica el problema de los delitos de comisión por omisión a la luz del principio de legalidad?

En estos supuestos, los delitos bajo esta variante implican que tanto la conformación del tipo delictivo de comisión por omisión como la interpretación que debe realizar el juzgador en estas modalidades, deberá partir de los elementos configurativos del tipo principal de acción y adicionarle el componente legal de donde emane la condición del garante (Pérez Duharte, 2007). Sólo aquellos casos en que el proceder omisivo sea tan grave como el activo y se verifique la equivalencia estructural, podrán ser sancionados.

En la doctrina, a fin de evitar o minimizar el conflicto entre la comisión por omisión y el principio de legalidad que generan sobre todo los delitos de comisión por omisión de configuración judicial, destacan las siguientes soluciones:

A. La creación en la Parte General del Código Penal de cláusulas de equivalencia o equiparación del actuar omisivo con el activo en aquellos casos donde dicho proceder sea de igual trascendencia para la protección y cuidado del bien jurídico, con la consecuente exigencia de la posición de garantía para el sujeto que produce el resultado y la predeterminación legal de esa obligación.

B. La conformación de tipos propios de comisión por omisión (Pérez Duharte, 2007).

El Código Penal cubano, teniendo en cuenta que la doctrina patria no ha mostrado suficiente interés en el tema que se analiza, adolece de cláusulas de equivalencia o equiparación del actuar omisivo con el activo (3). Sin embargo, de adoptar en su Parte General esta cláusula, obligaría a precisar las fuentes de donde se deriven las obligaciones: ley, contrato o hecho precedente; así como las reglas de conductas sociales con consecuencias jurídicas que deberán quedar circunscriptas a la ley, los decretos-leyes, decretos y resoluciones, que es de donde nace el deber de garante (obligación jurídica de actuar, la que se localiza a su vez en el sistema normativo en general). Ello a fin de juzgar los delitos de comisión por omisión que carecen de formulación expresa en el Código Penal.

(3) Sí la poseen, por ejemplo, los códigos penales de: España (artículo 11), Brasil (artículo 13), Ecuador (artículo 12), Colombia (artículo 25), El Salvador (artículo 22), Paraguay (artículo 15). 
Tal equiparación, en consideración de Pérez Duharte (2007) entre el proceder omisivo y el activo implicará el razonamiento de un grupo de aspectos que posibilitarán no sólo imputar el proceder omisivo en virtud de un precepto comisivo, sino también medir el grado de sanción a imponer por el órgano juzgador. A saber:

- La creación del peligro de lesión o el aumento del ya existente.

- La trascendencia y valía del bien jurídico afectado.

- La significación social de la conducta.

- La voluntad del legislador deducible de la concepción normativa.

- La trascendencia legal de la fuente de donde emana la obligación del garante.

En fin, la cláusula de equiparación constituye una solución que ofrece respeto y seguridad al principio de legalidad y a cada uno de sus presupuestos. Por otra parte, una tendencia a la conformación de tipos propios de comisión por omisión no resultaría ventajoso para el Código Penal ni para el ordenamiento jurídico porque a la postre conduciría a una norma en extremo casuística. Una normativa de este tipo por su carácter particular y delimitador al describir cada circunstancia en que se habrá de aplicar, no podría dar respuesta al surgimiento de nuevas problemáticas ni nuevas figuras delictivas.

Como una forma de validar las valoraciones expuestas se aplicó una encuesta no probabilística a 30 juristas que realizan su ejercicio en el campo de acción penal con una experiencia profesional promedio de 10 años. Esta técnica arrojó percepciones subjetivas de estos operadores jurídicos que resultaron útiles para examinar el nivel de conocimiento sobre la comisión por omisión como modalidad de la conducta penalmente relevante y las deficiencias asociadas a su regulación y aplicación en el contexto cubano. Antes de indagar directamente sobre los particulares de los delitos de comisión por omisión se dirigió el estudio hacia la comprobación de si han aumentado los procesos penales donde se exija responsabilidad penal médica por mala praxis; en relación con lo que el 78,4\% expresó que sí, y el $66,1 \%$ manifestó haber conocido durante su práctica profesional de la ocurrencia de este tipo de casos.

Al preguntarles sobre los elementos del delito, se advierte que la mayoría le atribuye un gran valor a la acción, catalogándola fundamentalmente como piedra angular o un presupuesto básico o esencial. Sólo dos de los encuestados (6,6\%) lo vieron como un rasgo más del delito. Sin embargo, en relación con las formas que puede adoptar un comportamiento penalmente relevante, el 11\% evidenció consenso en que estas pueden ser la acción, la omisión y la comisión por omisión. El 
89\% no mencionó la comisión por omisión, lo que sugiere, tal vez motivado por la propia praxis, un olvido de esta modalidad de la conducta delictiva.

Para profundizar en esa dirección se hurgó sobre los elementos que permiten identificar a un profesional del derecho la presencia de un delito de comisión por omisión. El 75,9\% mostró desconocimiento sobre ese aspecto. El resto expuso como elementos que distinguen la presencia de la comisión por omisión: el deber de garante, la omisión de una norma imperativa, un dejar de hacer que produce un resultado de hacer, así como la dualidad de normas afectadas dirigidas, una a no provocar el resultado y otra a realizar el acto omitido.

De manera general, aunque no existe una diferencia considerable entre los que opinan que en nuestro país se cuenta con las herramientas teórico-normativas y metodológicas necesarias para la evaluación de la responsabilidad penal médica en comisión por omisión, prevalecen $(57,9 \%)$ los que defienden que aún estas no son suficiente. En esta dirección, la doctrina y la legislación contemporánea insisten en regular de alguna forma esta modalidad de la conducta, debido a que su mal empleo o vulneración puede ocasionar una violación del principio de legalidad. Como solución a ello, de las tendencias existentes el 58\% considera como la más acertada la creación de reglas generales que autoricen la equiparación y el juzgamiento de estos delitos. El 32\% la estructuración de tipos penales y/o figuras derivadas en la Parte Especial de los códigos que regulen esta variante, mientras que sólo el $10 \%$ piensa que lo correcto sería facultar al órgano jurisdiccional para la determinación de las mismas atendiendo al caso concreto que se resuelve.

A manera de resumen, se puede decir que como resultado de la aplicación de esta técnica se corrobora cierto desconocimiento teórico-normativo sobre los delitos de comisión por omisión. Ello limita el camino a seguir para una correcta evaluación de la responsabilidad penal médica en casos de esta naturaleza. A la vez confirma la necesidad de establecer propuestas de orden teórico-normativo y metodológico en este sentido, a lo cual dedicamos el próximo epígrafe.

\section{Una propuesta para el ordenamiento jurídico cubano y la praxis judicial}

El estudio teórico-doctrinal realizado de la comisión por omisión como modalidad de la conducta penalmente relevante, también generadora de responsabilidad penal médica por los resultados de daño a la vida y salud de las personas, posibilitó la formulación de pautas para su determinación en la praxis judicial cubana. Estas se organizan en tres grupos según su contenido y función: de orden teórico, normativo y metodológico.

En el orden teórico se propone: 
1. Acoger sobre las fuentes del deber de garante, las dos concepciones teóricas existentes en su integración: formal y material (teoría material-formal). Ello permitirá tanto esclarecer las relaciones del sujeto con respecto al bien jurídico como valorar las respectivas fuentes de donde surgen tales relaciones.

2. Considerar, siguiendo los criterios de Pérez Duharte (2007) que la omisión impropia o comisión por omisión, se caracteriza por:

- Un resultado trasformador del referente real, cambio y mutación perceptibles en lo externo, coincidente con lo apuntado para el actuar activo.

- La simbiosis normativa, expresada en la dualidad de las normas afectadas; una genérica y prohibitiva, que dispone no producir el resultado ( $v$. gr. no matarás) y otra concreta e imperativa que ordena efectuar el acto omitido que evitaría la producción del resultado ( $\nu$. gr. El facultativo está obligado a realizar el acto médico correspondiente según la lex artis). La respuesta legal la ofrece el orden jurídico en su visión sistémica, por lo que el intérprete debe relacionar el tipo penal de acción con el sustento reglamentario de donde brota la obligación del garante.

- El bien jurídico tutelado se lacera por medio de un actuar diferente al exigido, apreciable y cambiante de la realidad, es decir, el no hacer logra un producto típico del hacer; no realizar el acto médico correspondiente causa su muerte.

En el orden normativo se propone:

1. Adoptar una cláusula en la Parte General del Código Penal sobre la omisión como modalidad de la conducta penalmente relevante que tiene su reflejo en determinadas figuras de delito establecidas en la Parte Especial. La que podría redactarse del siguiente modo:

Los delitos que consistan en la producción de un resultado sólo se entenderán cometidos por omisión cuando la no evitación del mismo, al infringir un especial deber jurídico del autor, equivalga, según el sentido del texto de la Ley, a su causación. A tal efecto se equiparará la omisión a la acción:

a) Cuando exista una específica obligación legal o contractual de actuar.

b) Cuando el omitente haya creado una ocasión de riesgo para el bien jurídicamente protegido mediante una acción u omisión precedente(4).

(4) Artículo 11. Código Penal de España. Ley Orgánica 10/1995, última modificación: 28 de abril de 2015. Referencia: BOE-A-1995-25444. Recuperado de http:/www.boe.es/legislación/códigos/ abril-pdf.php?fich=038-Codigo-Penal-y-legislacion-complementaria.pdf 
2. Establecer en el ordenamiento legal de Salud Pública los preceptos siguientes:

A) En caso de no aceptar la aplicación del tratamiento prescrito se le propondrá al paciente o usuario la firma del alta voluntaria. Si no la firmara, la dirección del centro sanitario, a propuesta del médico responsable, podrá disponer el alta forzosa en las condiciones reguladas por la ley, exceptuando de esta regla los casos en que existan tratamientos alternativos, aunque tengan carácter paliativo, siempre que los preste el centro sanitario y el paciente acepte recibirlo. Estas circunstancias quedarán documentadas.

En el caso de que el paciente no acepte el acta, la dirección del centro, previa comprobación del informe clínico correspondiente, oirá al paciente y, si persiste en su negativa, lo pondrá en conocimiento del juez para que confirme o revoque la decisión.

B) Si el paciente, debidamente informado, no accediera a someterse a un examen o tratamiento que el médico considerase necesario, o si exigiera del médico un procedimiento que este, por razones científicas o éticas, juzga inadecuado o inaceptable, el médico quedará dispensado de su obligación de asistencia.

C) El hecho de no aceptar el tratamiento prescrito no dará lugar al alta forzosa cuando existan tratamientos alternativos, aunque tengan carácter paliativo, siempre que los preste el centro y el paciente acepte recibirlos.

\section{En el orden metodológico se propone:}

Coincidiendo con Gómez Rivero (2003) cuya contribución teórica asumimos y sistematizamos en las próximas líneas, se han de distinguir dos momentos para las exigencias de la equivalencia estructural. Estos son:

Primer momento (presupuesto del juicio de imputación): destinado a la determinación del juicio de imputación. En este momento se ha de determinar si la no realización de la conducta debida crea un riesgo o contribuye de otra forma a que un riesgo externo se realice en un resultado, acrecentándose el peligro de su producción. Constituye un juicio previo al que decide tanto si el resultado es finalmente imputable a la omisión, como el título bajo el que deba atribuirse la responsabilidad del omitente.

Para ello, como punto de partida, se deben determinar los presupuestos bajo los cuales la omisión adquiere relevancia penal por estar el omitente en condiciones 
de responder del resultado desde el punto vista normativo. En consecuencia, se debe

1. Determinar que el sujeto, en este caso el médico, se encuentra en una posición de garante (Determinación de los presupuestos de la posición de garante del médico)(5). Para lo cual se requiere relacionar los criterios que delimitan el contenido y alcance de la obligación de garantía del facultativo:

A) Presupuesto mínimo: la existencia de una relación médico-paciente. La preexistencia de esta relación presupone un acto de asunción que genera una confianza en el paciente que provoca el abandono de otras medidas de protección. No obstante, debe evaluarse que

A.1. La libertad del médico de elegir a su arbitrio si asume o no el tratamiento de un determinado paciente queda vedado cuando su actividad se desarrolla en centros públicos como acontece en el país.

A.2. Cuando el paciente quiera poner fin al compromiso asumido por el médico, en un contexto hospitalario o de internamiento y esto representa una situación de riesgo para su vida, se distinguen dos supuestos para determinar si el médico continúa conservando su posición de garantía, de tal forma que si se limita a respetar la voluntad del paciente tendría que responder como comitente omisivo por el resultado lesivo que se termine produciendo:

A.2.1. Supuestos en los que el enfermo que se opone al tratamiento tiene la voluntad de poner fin a su vida. No se cancela, de por sí, la obligación de garantía del médico, salvo que el sujeto persista en su deseo de morir y como expresión del respeto al principio de autonomía no se le practiquen otros procederes médicos. Se observará propuesta normativa No 2-A) (Vid supra).

A.2.2. Supuestos en los que la negativa al tratamiento no está motivada por la voluntad de morir. Tal vez responde a convicciones religiosas o de cualquier otra índole. En este supuesto se debe determinar:

(5) Esto sucede cuando existe la obligación legal (contractual en los casos de la medicina privada en otros países) de actuar o se da un supuesto de injerencia, los que se concretan conforme a baremos materiales exigiendo una situación de proximidad jurídica entre la omisión y resultado. No puede olvidarse que la formulación de las fuentes del deber de obrar surge con una finalidad inequívoca: la de trazar los presupuestos a partir de los cuales pueda formularse un juicio de equivalencia entre un comportamiento activo y otro omisivo. 
A.2.2.a) Si la negativa a la terapia determina un empeoramiento al estado de salud, pero sin avecinar todavía una situación inminente de pérdida de la vida.

En estos supuestos, se considera la imposibilidad de fundamentar cualquier posición de garantía del facultativo. Lo contrario supondría desnaturalizar la razón que sustenta el diseño legal de la posición de garante y, con ella, su genuina función; implicaría exigir más al omitente garante que al que causa el resultado mediante un comportamiento activo. Igualmente, porque se daría al traste con el derecho de información del paciente que se expresa en la institución del consentimiento informado. En este sentido debe establecerse en el orden normativo asociado a la regulación del consentimiento informado lo planteado en la propuesta normativa No 2-B). (Vid supra).

A.2.2.b) Si la negativa a la terapia está marcada por la aparición de una situación irreversible que supone un peligro inminente para la vida.

En estos supuestos el médico bajo cuyo cuidado se encuentra el paciente, estará obligado a actuar (el deber de garante no queda cancelado) de forma tal que, si no lo hace y concurren los requisitos de equivalencia estructural, se sitúa en condiciones de responder por un homicidio en comisión por omisión. El interés que trasluce la opción legislativa de preservar la vida incluso en los casos en que el propio interesado tiene voluntad de morir ( $v$.gr. auxilio al suicidio) se convierte en argumento con el que sostener, con más contundencia aun, que la posición de garantía del médico no puede ceder ante la persistencia de una actitud del paciente que ni siquiera tiene el propósito de morir, sino sólo de ser fiel, hasta el final, a sus creencias y convicciones, de la índole que sean.

Ahora bien, es necesario que el paciente no se haya sustraído totalmente al compromiso del que trae su origen la asistencia médica, ya sea porque no pueda ( $v$.gr. lo que sucede en el ámbito de las relaciones penitenciarias (6)) o simplemente porque no quisiera hacerlo ( $\nu . g r$. los supuestos de negativa a la transfusión por parte de los Testigos de Je-

(6) El recluso no puede sustraerse al control médico debido a la especial relación de sujeción que le vincula con la Administración penitenciaria. Por ello, aun cuando quisiera cancelar cualquier compromiso de prestación asistencial se vería imposibilitado para hacerlo. Desde estos esquemas resulta imposible decir que quiebran los presupuestos que fundamentan dicha relación asistencial y, con ello, la posición de garantía del médico. 
hová(7)). Para este último caso puede adoptarse en el orden normativo lo establecido en la propuesta normativa o 2-C). (Vid supra).

Estos son los supuestos en lo que la renuncia al tratamiento impide cancelar la obligación de actuar médico. Fuera de estos casos, allí donde el paciente pueda y quiera sustraerse por completo a recibir cualquier tipo de prestación sanitaria, anulando totalmente los vínculos que en su día fundamentaron una relación médico-paciente, decaería cualquier responsabilidad médica en comisión por omisión.

B) Determinación de los límites hasta los que se extiende la posición de garantía del facultativo.

B.1. El deber de garante no rebasa la dolencia concreta respecto a la cual se asume la obligación de medios, entendida como la procura de la curación o mejora de dicho padecimiento.

B.2. El facultativo no está obligado a realizar aquellas intervenciones que, pese a ser solicitadas por el paciente, no responden a una finalidad curativa o no están indicadas conforme a las reglas de la lex artis.

B.3. El especialista que ha asumido el tratamiento del paciente de una afección concreta responde de las omisiones relativas a la misma, no así respecto a otras posibles patologías ajenas a aquella que en el curso del tratamiento pudieran aparecer o descubrirse, no relacionadas directamente.

B.4. En tanto que el compromiso médico se extiende al correcto tratamiento de la dolencia en cuestión, dicha posición de garantía no puede ceñirse a los actos que a él corresponda realizar de forma inmediata y personal, sino también a todos los que, de forma indirecta, forman parte del tratamiento que prescribe. Este último aspecto cobra suma importancia a la hora de delimitar la responsabilidad de un facultativo respecto a la actuación de otros miembros de su equipo (8).

(7) En ellos, en efecto, lo normal es que el paciente siga demandando asistencia sanitaria, si bien supeditada a la condición de que no se le practique una transfusión sanguínea. Esa actitud se traduce en que el paciente no rompe la relación de compromiso asistencial que está en la base de la posición de garantiza del médico. El Testigo de Jehová quiere ser curado y, por ello, sigue solicitando asistencia y los servicios de un profesional. De esta forma, acepta aun mantenerse dentro del círculo de acción de la asistencia, sin que, por tanto, puedan considerarse canceladas las bases que fundamentan el deber de obrar del médico.

(8) Sobre la responsabilidad penal médica en el marco del trabajo en equipo, véase Bernate Ochoa (2008); Maraver Gómez (2007). 
2. Determinar que la omisión del garante equivalga a su causación activa (Relevancia penal de la omisión como presupuesto del juicio de atribución normativa).

A) Creación de una situación de peligro para el bien jurídico con relevancia penal. Puede ser por negligencia, impericia o inobservancia de los reglamentos.

Primero y como requisito básico, se debe identificar una omisión concreta que debió realizar el facultativo y que sirva de base a los posteriores juicios de desvalor. Se trata de comprobar que su pasividad tenía capacidad para condicionar, determinar o favorecer mediante la omisión de una contribución concreta la lesión del bien jurídico; o sea, de exigir que, más allá de la posibilidad de que el garante pueda influir con su omisión de forma genérica en la evitación del hecho, la misma se haya identificado como una de aquellas que está, al menos a priori, en condiciones de incidir de modo específico y determinado en la realización del resultado y que, por tanto, configura la situación de peligrosidad.

B) Comprobación de que el comportamiento del garante representa una omisión no cubierta por el riesgo permitido y que incrementa las posibilidades de producción del resultado.

Significa que sólo cuando pueda predicarse que la omisión aumenta desde una perspectiva ex ante de forma relevante las posibilidades de producción del resultado, se dan las bases para una posible responsabilidad penal. Esta exigencia de verificar un aumento relevante de las posibilidades de lesión reclama que el acto concreto que omite el garante tuviera capacidad para incidir de forma directa e inmediata en la evitación del resultado, sin necesidad de interponer eslabones intermedios. De lo contrario, si la eficacia salvadora de la acción que omite hubiera de mediatizare por la interposición de otros cursos causales, la contribución que representa su conducta omisiva quedaría debilitada $\mathrm{y}$, con ello, el incremento de riesgo que significa, que difícilmente podría dar paso a un juicio de desvalor penal conforme al expediente de la comisión por omisión.

Sólo cuando se dieran todos estos requisitos que han de ser objeto de evaluación en el marco del primer momento, podría hablarse de la concurrencia de los presupuestos que permiten plantear en el ámbito omisivo el desvalor de la conducta penalmente relevante como presupuesto del juicio de atribución normativa del resultado que finalmente se produzca. 
Segundo momento (imputación del resultado producido): destinado a la determinación y argumentación de la imputación del resultado producido por la omisión del garante. En este caso a la hora de imputar el resultado producido se debe evaluar:

1. La realización del riesgo en el resultado. Se trata de verificar que la realización del riesgo es imputable normativamente al comportamiento omisivo.

Una vez comprobado que la omisión representa una conducta no permitida que incrementa las posibilidades de producción del resultado (desvalor de acción), se debe constatar que efectivamente la lesión producida es imputable a la misma (desvalor de resultado), a partir de la fórmula manejada por la doctrina de que la acción omitida habría evitado el resultado con una probabilidad rayana en la certeza, y es justamente su ausencia la que determina que se acabe realizando en aquel. Adicionalmente, de forma paralela a lo que sucede en la acción, habrá de verificarse que el resultado producido es uno de los que la norma pretendía evitar al consagrar la específica posición de garantía.

2. Si el alcance de la contribución lo es a título de autoría o participación.

Para su determinación se requiere tener en cuenta la concreta incidencia de la conducta omisiva en el resultado. La responsabilidad del facultativo como comitente omisivo habrá de valorarse por regla general como una forma de autoría ejecutiva, siendo excepcionales los casos de complicidad, cooperación necesaria e incluso de autoría mediata. La razón por la que esto sea así resulta de la propia morfología de supuestos en los que se contextualizan las conductas médicas omisivas, caracterizados porque el deber de actuar del médico encuentra su origen directo en la contención de los riesgos que afecten al paciente respecto al que ha asumido un compromiso de asistencia. Por su parte, los supuestos de complicidad o cooperación necesaria habrán de apreciarse allí donde la pasividad del garante sea meramente favorecedora de la conducta de un tercero (9).

\section{Consideraciones finales}

La responsabilidad penal del médico deriva de una conducta penalmente relevante que reúne los elementos constitutivos del delito y que también admite la posibilidad de su comisión por omisión. Esta se fundamenta en la especial posición de garantía del médico en el marco de la relación con el paciente y la identidad estructural entre el comportamiento activo y la comisión omisiva. Ello permite tanto esclarecer las relaciones del galeno con respecto al bien jurídico como valorar las respectivas fuentes de donde surgen tales relaciones.

(9) Para profundizar sobre la participación en los supuestos omisivos, véase Pérez Duharte (2007). 
El ordenamiento jurídico cubano en relación con la comisión por omisión ha ofrecido como solución la interpretación mediante los delitos de configuración judicial con los riesgos de vulneración al principio de legalidad que ello supone. En estos casos es el Tribunal, al momento de aplicar la norma, el que lleva a cabo la configuración, al no existir de modo expreso la omisión impropia, conforme a la creación de cláusulas de equivalencia o equiparación del actuar omisivo con el activo en aquellos supuestos donde dicho proceder sea de igual trascendencia para la protección y cuidado del bien jurídico.

El recorrido teórico-doctrinal realizado posibilitó la formulación de propuestas teóricas, normativas y metodológicas para la evaluación de la responsabilidad penal del médico en comisión por omisión. Estas revisten importancia en el proceso de perfección normativa, interpretación y aplicación de las disposiciones existentes. Las de índole metodológicas se agrupan en dos momentos: Primer momento (presupuestos del juicio de imputación): destinado a la determinación del juicio de imputación. Segundo momento (imputación del resultado producido): reservado a la determinación y argumentación de la imputación del resultado producido por la omisión del garante.

\section{Referencias bibliográficas}

Bacigalupo, Z. E. (1996). Manual de Derecho Penal. Parte General (3ª reimpresión). Santa Fe de Bogotá - Colombia: Editorial Temis S.A.

Baquero Vernier, U. (1983). Derecho Penal General (Vol. I). Santiago de Cuba: Facultad de Derecho. Universidad de Oriente. ENSPES.

Bernate Ochoa, F. (2008). Responsabilidad penal médica, trabajo en equipo y principio de confianza. Prolegómenos: derechos y valores, XI(21), (pp. 65-80).

Bustos Ramírez, J. J. y Hormazábal Malarée, H. (1997). Lecciones de derecho penal (Vol. I). Madrid: Editorial Trotta.

Cobo del Rosal, M. y Vives Antón, T. S. (1987). Derecho Penal Parte General. España: Tirant lo Blanch.

Creus, C. (1992). Derecho penal. Parte general (3a ed. actualizada y ampliada). Argentina: Editorial Astrea.

Fontán Balestra, C. (1998). Derecho Penal. Introducción y Parte general (Actualizado por Guillermo A. C. Ledesma). Buenos Aires, Argentina: Abeledo-Perrot.

Gómez Rivero, M. del C. (2003). La responsabilidad penal del médico. Valencia: Tirant lo Blanch. 
Luzón Cuesta, J. M. (1997). Compendio de Derecho Penal. Parte General (9a ed.). Madrid: Editorial Dykinson.

Luzón Peña (1996). Participación por omisión y omisión de impedir determinados delitos. La Ley.

Maraver Gómez, M. (2007). El principio de confianza en el Derecho Penal. Un estudio sobre la aplicación del principio de autorresponsabilidad en la teoría de la imputación objetiva (Tesis doctoral). Universidad Autónoma de Madrid, Madrid.

Mir Puig, S. (2002). Derecho Penal, Parte General (6 ed.). Barcelona: Editorial Reppertor.

Muñoz Conde, F. (1991). Teoría general del delito. $2^{\text {a }}$ ed. Valencia: Tirant lo Blanch.

Muñoz Conde, F. (2003). Prólogo. En La responsabilidad penal del médico (pp. 15-18). Valencia: Tirant lo Blanch.

Pérez Duharte, A. (2007). La autoría en los delitos omisivos (Tesis doctoral). Universidad de Oriente, Santiago de Cuba.

Pérez Duharte, A. (2015). La conducta omisiva y la determinación de autores. En Temas de Derecho Penal Parte General (pp. 159-191). La Habana: Editora My. Gral. Ignacio Agramonte y Loynaz.

Plascencia Villanueva, R. (2004). Teoría del delito. $3^{\text {a }}$ reimpr. México: Universidad Nacional Autónoma de México.

Quirós Pírez, R. (2005). Manual de Derecho Penal (Vol. I). La Habana: Félix Varela.

Rivero García, D. y Bertot Yero, M. C. (2013). Código Penal de la República de Cuba (Anotado con las Disposiciones del CGTSP). La Habana: Ediciones ONBC.

Zaffaroni, E. R.; Slokar, A. y Alagia, A. (2002). Derecho Penal: parte general (2a edición). Buenos Aires, Argentina: Ediar.

\section{Fuentes legales}

Acuerdo Conjunto del Ministerio del Interior, el Tribunal Supremo Popular, la Fiscalía General de la República y Ministerio de Salud Pública, del 3 de mayo de 1983. 
Código Orgánico Integral de la República de Ecuador, SR.O. No 180 de 10 de febrero de 2004. Ed. GAB.2014.

Código Orgánico Procesal Penal de Venezuela, Caracas, de 25 de julio de 2000 (Gaceta Oficial, No 37.022, Extraordinaria, de 25 de agosto del 2000). Ediciones DABOSAN.

Código Penal Argentino. Ley 11.179. Texto ordenado. Decreto 3992/84 y modificatorias hasta abril de 2004 y última actualización B. O. 11/01/2005. Sitio de información quilmeña quilmeslegal.com.

Código Penal de Colombia. Ley No 600 de 24 de julio de 2000. Recuperado de http://perso.unifer.ch/derechopenal/assest/files/legislacion/1-20130808-01.pdf

Código Penal de España. Ley Orgánica 10/1995, última modificación: 28 de abril de 2015. Referencia: BOE-A-1995-25444. Recuperado de http:/www.boe.es/ legislación/códigos/abril-pdf.php?fich=038-Codigo-Penal-y-legislacion-complementaria.pdf

Colombia. Ley No 1751, de 16 de febrero de 2015. Recuperado de https://www. minsalud.gov.co/Normatividad_Nuevo/Ley\%201751\%20de\%202015.pdf

Ecuador. Ley No 67/2006, de 14 de diciembre, de Derechos y amparo del paciente. Recuperado de http://www.cicad.oas.org/fortalecimiento_institucional/ legislations/PDF/EC/ley_organica_de_salud.pdf

España. Ley No 41/2002 de 14 de noviembre, básica reguladora de la autonomía del paciente y de derechos y obligaciones en materia de información y documentación clínica. Recuperado de http://www.oposiciones-kuma.com/file.php/1/ auxiliar_admtvo/DEMO\%20apuntes\%20Juridico\%20SCS\%20Aux\%20Admtvo.pdf

Instrucción No 110 del Consejo de Gobierno del Tribunal Supremo Popular del 9 de julio de 1983.

Ley 41 de 1983, de Salud Pública, Recuperado de http://www.sld.cu/galerias/ pdf/sitios/rehabilitacion-bal/ley_41_83_de_la_salud_publica.pdf

Fecha de recepción: 29-03-2019 Fecha de aceptación: 13-09-2019 
